\title{
Satisfaction and convenience of using terpenoid- impregnated eyelid wipes and teaching method in people without blepharitis
}

This article was published in the following Dove Press journal:

Clinical Ophthalmology

\section{Tian Yu Qiu' \\ Sharon $\mathrm{Yeo}^{2}$ \\ Louis Tong ${ }^{1-4}$}

'Yong Loo Lin School of Medicine, National University of Singapore,

${ }^{2}$ Singapore Eye Research Institute,

${ }^{3}$ Singapore National Eye Centre,

${ }^{4}$ Duke-NUS Medical School, Singapore
Correspondence: Louis Tong Singapore National Eye Centre, II, Third Hospital Avenue, Singapore I6875 I

Tel +6598186221

Fax +6562277290

Email louis.tong.h.t@singhealth.com.sg
Purpose: Demodex infestations cause blepharitis and are difficult to treat. Recently, a new type of eyelid wipes with terpenoids has been found effective. We aim to evaluate patient satisfaction after short-term use and compare two teaching modalities on the techniques of use.

Patients and methods: Eligible participants were taught to use eyelid wipes (Cliradex $\left.{ }^{\circledR}\right)$ by either live or online video demonstration based on random allocation. Participants used the wipes twice daily for a week. All participants had prior evaluation of socioeconomic status, dry eye symptoms, and meibomian gland features. After 1 week, competence of use was assessed by participants showing their technique to the investigator, and a questionnaire on comfort, ease, and convenience of use was administered. Higher scores indicate greater satisfaction, and these levels are compared among the two teaching modalities using chi square.

Results: A total of 50 participants were recruited, with a mean age of $42 \pm 16$ years, and $88 \%$ of the participants were females. Overall, median comfort level was 4.0 (range: 1-6), ease level was 5.0 (3-6), and convenience level was 5.0 (2-6). Median stinging was 2.0 (1-4), which corresponded to some but mild stinging. The median competence level was 4.0 (2-4), which corresponded to excellent competence. These satisfactory levels (ease, comfort, and convenience) experienced were not significantly associated with different socioeconomic indicators, that is, housing type, income, highest education level, and were not different between teaching methods $(p>0.05)$

Conclusion: Short-term use of Cliradex eyelid wipes seems to be acceptable to most people. The teaching instructions before using these wipes were equally effective - whether live or online video demonstration was used.

Keywords: dry eye, blepharitis, meibomian gland dysfunction, Demodex, eyelid wipes

\section{Introduction}

Dry eye is a highly prevalent multifactorial disease affecting $14 \%-33 \%$ of adults worldwide. ${ }^{1-5}$ Mild to moderate forms of dry eyes are most common and are associated with significant healthcare and economic burden. ${ }^{4-6}$ An interplay of factors including environmental, living habits, nutrition, and underlying systemic disease contributes to dry eyes and significant decrease in quality of life. . $^{3,4-9}$

Dry eyes refractory to treatment could potentially be due to eyelid infestation by Demodex mites. ${ }^{10-13}$ The Demodex mites can induce lid margin inflammation and cause peri-follicular cuffing with edema and, by living in meibomian glands,,${ }^{14}$ can potentially obstruct the glandular ducts and deplete the tear film of meibum lipids. ${ }^{15}$ The current treatment for demodicosis-related blepharitis is tea tree oil, which contains an active ingredient (terpinen-4-ol) that is effective in killing Demodex mites. ${ }^{16-18}$ 
Previous studies have shown that terpinen-4-ol has both antimicrobial and anti-inflammatory activity in humans by suppressing pro-inflammatory cytokines. ${ }^{17,19}$ One of the commercially available preparations that contains terpinen-4-ol is the Cliradex ${ }^{\circledR}$ lid wipes (Bio-Tissue, Doral, FL, USA). This product has no preservatives and has been used as lash and facial cleanser and may help in relieving symptoms associated with dry eye caused by blepharitis. ${ }^{20-23}$ Its clinical efficacy is shown in a study by Gao et al, in which all of the 24 patients recruited had improvement in ocular itching with 4 weeks of $5 \%$ tea tree oil ointment, out of which 16 patients were relieved completely. ${ }^{24}$ However, two patients experienced a little irritation, but this was not related to lack of response to treatment, and how the patients were instructed to use the ointment was not reported. ${ }^{24}$

The terpinenes are known to be potentially irritating to the eyes, ${ }^{25}$ stinging has been documented in the context where clinical signs of blepharitis were improving, but it has not been documented in the use of wipes in a person without blepharitis. Therefore, it is critical that the technique of application is correct, so that minimal leakage to the conjunctiva occurs. The method of instruction can potentially impact on how tea tree oil is applied. In addition, eyelid wipes are different from ointments, and there have not been any studies that advise on the most suitable form of training for potential users nor any consensus on what is the best technique of application of the terpenoid-impregnated wipes.

Since blepharitis is a chronic disease, prolonged treatment may be necessary. Quite apart from the proven efficacy of tea tree oil, if training on the use of eyelid wipes is associated with minimal to no discomfort, it will impact on the acceptance of the treatment, the perseverance of using the wipes, and likely the long-term success of this type of therapy. The manufacturers also recommend Cliradex wipes for patients with blepharitis without evidence of Demodex infestations, although this has not been evaluated in published studies.

In this study, we aimed to evaluate satisfaction level of Cliradex eyelid wipes in terms of ease, comfort, and convenience of use and compare two modalities of teaching patients on the use of these wipes.

\section{Materials and methods Study design}

This was a randomized observer-masked parallel study. All participants were either recruited from a clinic in Singapore National Eye Center (SNEC) or by word of mouth. The study received approval from the Centralized Institutional Review
Board of Singhealth Services, and all participants provided written informed consent. All procedures complied with the tenets of the Helsinki Declaration on human research. This is not a randomized treatment trial; hence, no treatment modalities are being compared, and use of the "treatment" device is uniform for all participants.

\section{Recruitment}

Participants fulfilled all the following criteria: aged $\geq 21$ years, possess a mobile phone, able to read basic English instructions, and agreeable to receive a daily text message through the mobile phone as a reminder to use the lid wipes during study period. These participants had not been previously diagnosed with blepharitis and did not have previous experience of using eyelid care products. We excluded participants who were pregnant, lactating, or planning a pregnancy.

\section{Method of randomization}

This is a parallel-group observer-masked randomized study involving a convenient sample size of 50 participants. Randomization was performed at the dry eye clinic of SNEC with each participant randomly selecting one of two types of envelopes, which comprised information of whether participant received video or live demonstration. A witness was present during the randomization process at the commencement of the study. There were a total of 25 envelopes of each type, such that there were an equal number of participants in each group. The code was then kept by an administrative staff who was not involved in the subsequent assessment of participants, that is, basic demographics, acceptability of wipe use, and so on.

\section{Method of demonstration}

Twenty-five participants received a live demonstration on the technique of applying the eyelid wipes. This demonstration was performed by a student who received prior standardized training by an opthalmologist on the correct technique of wipe use (refer to Supplementary materials: script for live demonstration and video demonstration link). A recording of the demonstration was performed for quality assurance and was assessed to be suitable by a study investigator. The other 25 participants were provided with an online link to a youtube video demonstration and were shown the video on a mobile phone. ${ }^{26}$ They had the option of further reviewing the same video whenever necessary. This video script was written and acted out by a student, and the entire process of 
video making was edited and supervised by an opthalmologist who is familiar with the techniques of using eyelid wipe. All 50 participants also received a daily SMS reminder at an agreed time as a reminder to use the wipes, but they were not required to reply or report on the time of use of the wipe.

\section{Study procedures}

On participants' first visit, they completed a Standard Patient Evaluation Eye Dryness questionnaire, ${ }^{27,28}$ and their eyelids were assessed clinically by a trained ophthalmologist.

The presence of "crusting" and "meibomian glands (MG) plaques" was rated as present or absent, and the regularity of MG orifices was rated as regular or irregular. Eyelid examination procedures have been reported in one of our previous papers. ${ }^{29}$ On the second visit 1 week later, the participants answered questions related to their socioeconomic status (housing type, income, and highest education level) and the outcome of the study. The staff who assessed the patients' basic demographics and study outcomes were blinded to the teaching method of each of the participants.

\section{Assessment of study outcomes}

Acceptability of Cliradex treatment was assessed based on an interviewer-administered questionnaire on the reported ease, comfort, and convenience of use, and each of these factors was graded on a scale of 6 steps from 1 to 6 , ranging from the most negative to the most positive. For example, in the assessment of comfort, the scale ranges from (1) extremely uncomfortable to (6) extremely comfortable (Supplementary materials). The interviewers have received prior training and memorized a standardized script when administering the questionnaire to ensure standardization.

Adverse stinging sensation was evaluated based on scale of $1-4$, where 4 is most stinging and 1 is no stinging.

Another outcome is whether participants were able to display the correct technique of eyelid cleaning competently at the end of the study. Thus, on the second visit, the participants had demonstrated their technique to a study investigator, and the competence of use was graded on a scale with four steps: ranging from 1 (unable to perform) to 4 (excellent performance). The script instructions have been divided into four steps (Supplementary materials). If all the four steps were deemed competent, a grade of "Excellent" would be assigned. If three-fourths of the steps were competent, a grade of "Reasonable" was assigned. If only two of the steps were correct, the grade given was "Needs improvement." When only one or none of the steps were performed correctly, the grade given was "Unable to perform." Actual wiping technique in step 4 includes the number of times of wiping, the length, direction, position, and accuracy of wiping motion.

\section{Statistical analysis}

The clinical parameters were presented and compared in each teaching group using independent two-tailed $t$-tests for continuous variables and chi-square tests for categorical variables.

Frequency distributions of all outcome variables were plotted on bar graphs. The outcome variables were evaluated as categories using chi-square tests or Fisher's exact probability tests, although for reference, the median and interquartile range of the raw findings were also reported. The effects of potential confounding variables such as age and socioeconomic status were controlled using a logistic regression model.

The level of statistical significance was set at alpha $<0.05$.

\section{Results}

Overall, $88 \%$ of the participants were females and the mean age was $42.7 \pm 16.5$ years. Demographics and clinical characteristics of the participants were found to be similar between the two teaching groups (Table 1). The clinical severity of symptoms and ocular surface signs suggest that these were not participants with overt blepharitis.

Overall, $58 \%$ of the participants were rated as excellent in their technique, and another $26 \%$ were rated as reasonably good technique. In other words, more than three-fourths were using the eyelid wipes correctly. Only 16\% needed some improvement. There was no difference in the competence between the two groups of participants $(p>0.05)$.

At the end of 1 week, the ease, comfort, convenience, and stinging experienced by participants was assessed by an investigator and the results are shown in Table 2, and the overall frequency of the responses is shown in bar charts (Figure 1). At least half of the participants (median) found the use of eyelid wipes to be "quite easy," "quite convenient," and "slightly comfortable." In terms of the level of stinging, the median corresponded to "some stinging but mild." Only one of the participants, a 50-year old woman who had been taught to use the wipes by a live demonstration, reported stinging to be "intolerable," despite having been graded as "excellent" in terms of technique. We did not find any factors that were different between those with good competency, defined as "reasonable" or "excellent" (42 participants) compared to those with poor competency, defined as "needs improvement" or "unable to perform" (eight participants). The median age of participants with poor competency versus good competency was 42 and 38 years, respectively. However, the difference was 
Table I Demographic and clinical characteristics of the participants

\begin{tabular}{|c|c|c|c|c|}
\hline $\begin{array}{l}\text { Demographic and clinical } \\
\text { characteristics }\end{array}$ & $\begin{array}{l}\text { Total } \\
(n=50)\end{array}$ & $\begin{array}{l}\text { Video* } \\
(\mathrm{n}=25)\end{array}$ & $\begin{array}{l}\text { Live** } \\
(n=25)\end{array}$ & $p$-value \\
\hline \multicolumn{5}{|l|}{ Demographics } \\
\hline \multicolumn{5}{|l|}{ Gender } \\
\hline Female, n (\%) & $44(88.0)$ & $22(88.0)$ & $22(88.0)$ & 1.000 \\
\hline Age, mean $\pm S D$ & $42.7 \pm 16.5$ & $40.2 \pm 15.8$ & $45.1 \pm 17.2$ & 0.298 \\
\hline \multicolumn{5}{|l|}{ Ethnicity } \\
\hline Chinese, $\mathrm{n}(\%)$ & $46(92.0)$ & $23(92.0)$ & $23(92.0)$ & $0.26 \mathrm{I}$ \\
\hline \multicolumn{5}{|l|}{ Socioeconomic indicators } \\
\hline \multicolumn{5}{|l|}{ Highest education } \\
\hline Up to A levels/diploma, $n$ (\%) & $33(66.0)$ & $18(72.0)$ & $15(60.0)$ & \\
\hline University and above, $\mathrm{n}(\%)$ & $17(34.0)$ & $7(28.0)$ & $10(40.0)$ & 0.551 \\
\hline \multicolumn{5}{|l|}{ Housing type } \\
\hline$\leq 4$ rooms, $\mathrm{n}(\%)$ & $21(42.0)$ & $8(32.0)$ & $13(52.0)$ & \\
\hline 5 room/executive, $\mathrm{n}(\%)$ & $25(50.0)$ & $14(56.0)$ & II (44.0) & \\
\hline Private, $\mathrm{n}(\%)$ & $4(8.0)$ & $3(12.0)$ & I $(4.0)$ & 0.279 \\
\hline \multicolumn{5}{|l|}{ Gross income } \\
\hline$\leq S \$ 3,000, \mathrm{n}(\%)$ & $30(60.0)$ & $15(60.0)$ & $15(60.0)$ & \\
\hline$>S \$ 3,000, n(\%)$ & $10(40.0)$ & $10(40.0)$ & $20(40.0)$ & 1.000 \\
\hline \multicolumn{5}{|l|}{ Clinical characteristics } \\
\hline SPEED score, mean \pm SD & $7.6 \pm 5.7$ & $7.2 \pm 5.3$ & $8.0 \pm 6.2$ & 0.624 \\
\hline Presence of crusting RE, $n(\%)^{* * *}$ & $5(10.0)$ & I (4.0) & $4(16.0)$ & 0.157 \\
\hline Presence of meibomian gland plaque RE, $n(\%) * * *$ & $18(36.0)$ & $9(36.0)$ & $9(36.0)$ & 1.000 \\
\hline Regularity of meibomian gland orifice RE, $\mathrm{n}(\%)^{* * *}$ & $45(90.0)$ & $24(96.0)$ & $21(84.0)$ & 0.157 \\
\hline
\end{tabular}

Notes: *These participants were given a link to an online video demonstration of the eyelid wipe technique. **These participants were given a live demonstration of the eyelid wipe technique. ***Baseline clinical characteristics of both eyes were taken but only the right eye characteristics were presented, as there is a significant correlation (based on Pearson correlation coefficient) between right and left eyes for the presence of crusting, plaque, or regularity $(R>0.6, p<0.0 \mathrm{I})$.

Abbreviations: RE, right Eye; S\$, Singapore dollars; SPEED, Standard Patient Evaluation Eye Dryness.

not statistically significant. Similarly, gender, race, education level, and income levels were not significantly different.

There were no differences in these outcomes between the participants who were given a live demonstration compared to those offered online video demonstrations. When the outcomes were adjusted for by age, gender, or socioeconomic status, there were still no differences between the teaching methods (all $p>0.05$ ).

Table 2 Competence of use assessed by investigator, ease, comfort, convenience, and stinging experienced by participants

\begin{tabular}{|c|c|c|c|c|}
\hline Factors affecting acceptability of Cliradex & $\begin{array}{l}\text { Total } \\
(n=50)\end{array}$ & $\begin{array}{l}\text { Video* } \\
(n=25)\end{array}$ & $\begin{array}{l}\text { Live** } \\
(n=25)\end{array}$ & $p$-value*** \\
\hline \multicolumn{5}{|l|}{ Acceptability of Cliradex - ease of use } \\
\hline Median (lower quartile, median, upper quartile) & $5(4,5,6)$ & $5(4,5,6)$ & $5(4,5,6)$ & \\
\hline Easy to extremely easy (grades 4-6), n (\%) & $47(94.0)$ & $25(100.0)$ & $22(88.0)$ & \\
\hline Extremely difficult to difficult (grades I-3), n (\%) & $3(6.0)$ & $0(0.0)$ & $3(12.0)$ & 0.235 \\
\hline \multicolumn{5}{|l|}{ Acceptability of Cliradex - comfort level } \\
\hline Median (lower quartile, median, upper quartile) & $4(3,4,5)$ & $4(3,4,5)$ & $3(3,3,4)$ & \\
\hline Slightly comfortable to extremely comfortable (grades 4-6), n (\%) & $26(52.0)$ & $16(64.0)$ & $10(40.0)$ & \\
\hline Extremely uncomfortable to slightly uncomfortable (grades I-3), n (\%) & $24(48.0)$ & $9(36.0)$ & $15(60.0)$ & 0.156 \\
\hline \multicolumn{5}{|l|}{ Acceptability of Cliradex - convenience } \\
\hline Median (lower quartile, median, upper quartile) & $5(4,5,5)$ & $5(5,5,5)$ & $5(4,5,6)$ & \\
\hline Convenient to extremely convenient (grades 4-6), n (\%) & $45(90.0)$ & $24(96.0)$ & $21(84.0)$ & \\
\hline Extremely inconvenient to inconvenient (grades I-3), n (\%) & $5(10.0)$ & I (4.0) & $4(16.0)$ & 0.349 \\
\hline \multicolumn{5}{|l|}{ Acceptability of Cliradex - stinging } \\
\hline Median (lower quartile, median, upper quartile) & $2(2,2,3)$ & $2(2,2,3)$ & $3(2,3,3)$ & \\
\hline Little/no stinging, to some but mild stinging (grade I-2), n (\%) & $26(52.0)$ & $14(56.0)$ & $12(48.0)$ & \\
\hline Quite bad stinging but goes away, to untolerable stinging (grade 3-4), n (\%) & $24(48.0)$ & II (44.0) & $13(52.0)$ & 0.473 \\
\hline \multicolumn{5}{|l|}{ Competence of use } \\
\hline Median (lower quartile, median, upper quartile) & $4(3,4,4)$ & $3(3,3,4)$ & $4(3,4,4)$ & \\
\hline Reasonable to excellent performance (grade 3-4), n (\%) & $42(84.0)$ & $20(80.0)$ & $22(88.0)$ & \\
\hline Unable to perform, to needs improvement (grade I-2), n (\%) & $8(16.0)$ & $5(20.0)$ & $3(12.0)$ & 0.70 \\
\hline
\end{tabular}

Notes: *These participants were given a link to an online video demonstration of the eyelid wipe technique. **These participants were given a live demonstration of the eyelid wipe technique. ***For comparing medians, Mann-Whitney $U$ test was used, and for comparing proportions in $2 \times 2$ contingency tables, the chi square test and Fisher's exact test were used. Cliradex ${ }^{\circledR}$ lid wipes (Bio-Tissue, Doral, FL, USA). 

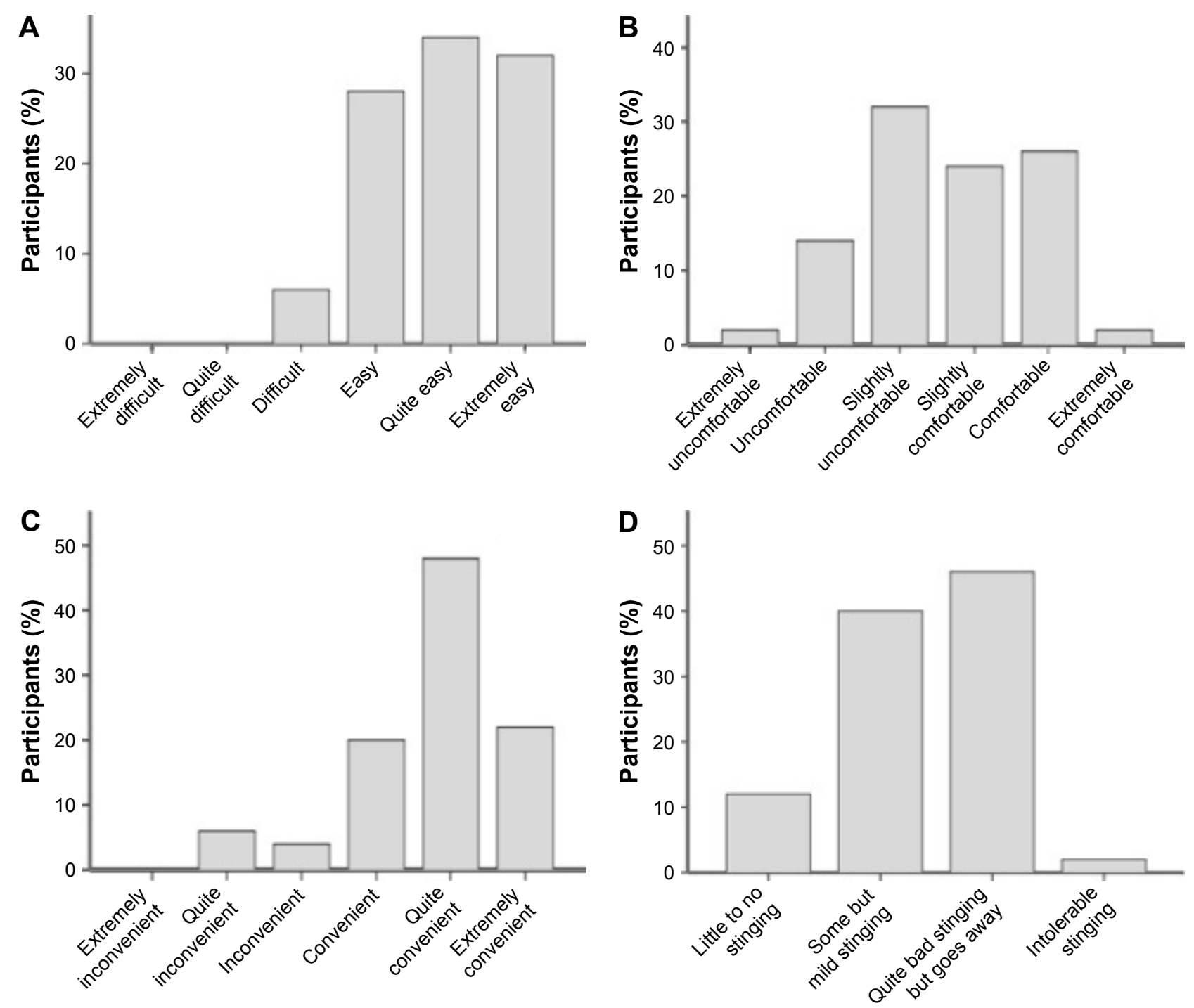

Figure I The overall frequency of ease, comfort, convenience, and stinging experienced by participants. (A) Ease levels, (B) comfort levels, (C) convenience levels, and (D) stinging levels.

\section{Discussion}

In this short study, we found the terpenene-containing wipes to be easy, comfortable, and convenient to use. Overall, some stinging sensation was experienced, but it seemed to be minimal. Both live and online video demonstrations were equally effective as a method of instruction to teach the technique of use. Most patients had a good technique when assessed by a trained evaluator.

Higher concentration of $50 \%$ tea tree oil scrub was able to kill mites but gave variable amount of irritation to the patients..$^{30}$ However, this adverse effect was found to be reduced if correct technique of application was performed to minimize spillage into eyes..$^{30}$ Hence, it is highly important to evaluate the instruction methods to ensure correct application technique and minimize adverse effects. No previous studies have compared the methods of teaching for the use of eyelid wipes.

As far as we know, there have been no previous studies on the practical issues encountered on the use of terpeneneisolated eyelid wipes. There has been one study done on tolerability and acceptability of another eyelid hygiene product (Blephagel; Laboratoires Thea, Clermont-Ferrand, France). ${ }^{12}$ Although Blephagel has been found acceptable for use after 21 days of use, it does not contain terpenoids and would not be expected to be efficacious in killing mites. A similar eyelid product that contains tea tree oil is Oust ${ }^{\mathrm{TM}}$ Demodex Cleanser ${ }^{31}$ (OCuSOFT, Richmond, TX, USA), but the adverse effects of using this preparation, if any, have not been reported. ${ }^{32}$

The strength of this study is the randomized design and the quality assurance measures such as daily reminders to 
use the eyelid wipes, training of study investigators, and recording of live demonstration performed by the investigators. Uniform training of investigators ensures consistency between teaching the participants. In addition, we also adjusted the outcomes by socioeconomic factors because we postulated that socioeconomic factors such as education level may affect the competence of use and their compliance to treatment as seen in patients on long-term medications such as statins. ${ }^{33,34}$ There is no issue of "desire to please" as this is not a treatment trial, and regardless of participants' study outcome, they would still be receiving the same treatment.

The main limitation of this study is the absence of older people and those with dry eye, which are the main target users in clinics. As this is a pilot-type study, we could not exclude a type 2 error especially in outcome variables where only a few participants were positive. It may not be cost-effective to conduct a large study just to increase the number of people who found it "not easy to use the Cliradex wipes." Other limitation includes the short duration of use of eyelid wipes as a single box will enable use of 1 month in actual clinical practice. We also did not evaluate non-English speakers or patients who are not Internet literate.

In clinical practice, demodicosis is a difficult form of blepharitis ${ }^{13,35}$ to treat, and its prevalence in elderly could be as high as $70 \%$ over 80 years of age. ${ }^{3,36}$ Although terpenoids, the active form of tea-tree oil, have been shown to be effective to kill mites, they are difficult to dissolve or formulate consistently. ${ }^{17}$ Since Cliradex wipe contains terpenoids, currently it is the only commercially available preparation that has been found to be effective against Demodex infestations. Application as ointment or emulsion may not be easy especially for old patients as it requires more coordination than using eyelid wipes. ${ }^{37}$ Therefore, the clinical significance of our findings is that this eyelid wipe is a potentially tolerable and easily applicable cleansing agent. The ease, comfort, and convenience of use, together with acceptable levels of stinging (adverse effect), should facilitate compliance in the longer term. ${ }^{12,22}$ Our study also suggests that if there were insufficient healthcare staff to demonstrate the use of these eyelid wipes, it may be equally acceptable for patients to be referred to an online resource, provided that the patients are Internet-savvy. However, we may not be able to extrapolate to all dry eye patients, since the mean age of the participants in this study seems to be younger than the age of the patients from our dry eye clinics. ${ }^{29,38}$

In conclusion, short-term use of Cliradex eyelid wipes would likely be acceptable for patients, assuming that these patients are of similar educational and cultural background as our participants. The teaching instructions before commencing the use of these wipes may either be demonstration by an experienced person or a pre-recorded online demonstration. Both the methods of teaching are equally useful in ensuring patients' competence of using the eyelid wipes and achieving similar satisfaction level.

\section{Acknowledgments}

This study was supported by grant NMRC \CSA $\backslash 045 \backslash 2012$ from the National Medical Research Council. We would like to thank Shauna Lim, Jason Ong, Joy Tan, and Gan Junlim for assistance in data collection and logistics for the study.

\section{Author contributions}

All authors contributed toward data analysis, drafting and critically revising the paper, gave final approval of the version to be published, and agree to be accountable for all aspects of the work.

\section{Disclosure}

The authors report no conflicts of interest in this work.

\section{References}

1. Gayton JL. Etiology, prevalence, and treatment of dry eye disease. Clin Ophthalmol. 2009;3:405-412.

2. Janine A. The epidemiology of dry eye disease: report of the epidemiological subcommittee of the international dry eye workshop. Ocul Surf. 2007;5(2):93-107.

3. Shah S, Jani H. Prevalence and associated factors of dry eye: our experience in patients above 40 years of age at a Tertiary Care Center. Oman J Ophthalmol. 2015;8(3):151-156.

4. Pflugfelder SC. Prevalence, burden, and pharmacoeconomics of dry eye disease. Am J Manag Care. 2008;14(3 Suppl):S102-S106.

5. Stapleton F, Garrett Q, Chan C, Craig JP. The epidemiology of dry eye disease. In: Chan C, editor. Dry Eye. 1st ed. Berlin/Heidelberg: SpringerVerlag; 2015:21-29.

6. McDonald M, Patel DA, Keith MS, Snedecor SJ. Economic and humanistic burden of dry eye disease in Europe, North America, and Asia: a systematic literature review. Ocul Surf. 2016;14(2):144-167.

7. Javadi MA, Feizi S. Dry eye syndrome. J Ophthalmic Vis Res. 2011; 6(3):192-198.

8. Thornton SP, Troyer E. Dry eye: inflammation \& nutrition. Ophthalmol Manag. 2006.

9. Paulsen AJ, Cruickshanks KJ, Fischer ME, et al. Dry eye in the beaver dam offspring study: prevalence, risk factors, and health-related quality of life. Am J Ophthalmol. 2014;157(4):799-806.

10. Liu J, Sheha H, Tseng SCG. Pathogenic role of Demodex mites in blepharitis. Curr Opin Allergy Clin Immunol. 2010;10(5):505-510.

11. Gunnarsdottir S, Kristmundsson A, Freeman MA, Bjornsson OM, Zoega GM. Demodex folliculorum, hársekkjamítill, dulin orsök hvarmabólgu [Demodex folliculorum a hidden cause of blepharitis]. Laeknabladid. 2016;102(5):231-235. Icelandic.

12. Doan S. Tolerability and acceptability of Blephagel: a novel eyelid hygiene aqueous gel. Clin Ophthalmol. 2012;6:71-77.

13. Zhao YE, Wu LP, Hu L, Xu JR. Association of blepharitis with Demodex: a meta-analysis. Ophthalmic Epidemiol. 2012;19(2):95-102.

14. English FP, Nutting WB. Demodicosis of ophthalmic concern. Am J Ophthalmol. 1981;91(3):362-372. 
15. Liu J, Sheha H, Tseng SC. Pathogenic role of Demodex mites in blepharitis. Curr Opin Allergy Clin Immunol. 2010;10(5):505-510.

16. Cheng AM, Sheha H, Tseng SC. Recent advances on ocular Demodex infestation. Curr Opin Ophthalmol. 2015;26(4):295-300.

17. Tighe S, Gao YY, Tseng SC. Terpinen-4-ol is the most active ingredient of tea tree oil to kill Demodex mites. Transl Vis Sci Technol. 2013;2(7):2.

18. Gao Y, Di Pascuale MA, $\mathrm{Li}$ W, et al. In vitro and in vivo killing of ocular Demodex by tea tree oil. Br J Ophthalmol. 2005;89(11):1468-1473.

19. Hart PH, Brand C, Carson CF, Riley TV, Prager RH, Finlay-Jones JJ. Terpinen-4-ol, the main component of the essential oil of Melaleuca alternifolia (tea tree oil), suppresses inflammatory mediator production by activated human monocytes. Inflamm Res. 2000;49(11):619-626.

20. Kobayashi A, Ide T, Fukumoto T, Miki E, Tsubota K, Toda I. Effects of a new eyelid shampoo on lid hygiene and eyelash length in patients with meibomian gland dysfunction: a comparative open study. J Ophthalmol. 2016;2016:4292570.

21. Yin Y, Gong L. Reversibility of gland dropout and significance of eyelid hygiene treatment in meibomian gland dysfunction. Cornea. 2017;36(3):332-337.

22. Benitez-Del-Castillo JM. How to promote and preserve eyelid health. Clin Ophthalmol. 2012;6:1689-1698.

23. Auw-Hadrich C, Reinhard T. Therapeutische Optionen bei chronischer Blepharitis unter Berücksichtigung der Evidenzlage [Treatment options for chronic blepharitis considering current evidence]. Ophthalmologe. 2016;113(12):1082-1085. German.

24. Gao YY, Xu DL, Huang IJ, Wang R, Tseng SC. Treatment of ocular itching associated with ocular demodicosis by $5 \%$ tea tree oil ointment. Cornea. 2012;31(1):14-17.

25. Ngo W, Jones LW, Srinivasan S, Bitton E. Discomfort over time associated with various ocular Demodex treatment products. Invest Ophthalmol Vis Sci. 2016;57(12):2838.

26. Cliradex Lidwipes Demonstration. Video available at: https://youtu. be/F0z33eoVIqM. Accessed December 19, 2017.
27. Asiedu K. Rasch analysis of the Standard Patient Evaluation of Eye Dryness questionnaire. Eye Contact Lens. 2017;43(6):394-398.

28. Ngo W, Situ P, Keir N, Korb D, Blackie C, Simpson T. Psychometric properties and validation of the Standard Patient Evaluation of Eye Dryness questionnaire. Cornea. 2013;32(9):1204-1210.

29. Tong L, Chaurasia SS, Mehta JS, Beuerman RW. Screening for meibomian gland disease: its relation to dry eye subtypes and symptoms in a tertiary referral clinic in Singapore. Invest Ophthalmol Vis Sci. 2010;51(7):3449-3454.

30. Gao YY, Di Pascuale MA, Li W, et al. In vitro and in vivo killing of ocular Demodex by tea tree oil. Br J Ophthalmol. 2005;89(11):1468-1473.

31. Karpecki PM. Getting a grip on blepharitis. Rev Optom. 2015;152(5): 26-29.

32. Yun SH, Levin F, Servat J. Demodex folliculitis presenting as periocular vesiculopustular rash. Orbit. 2013;32(6):370-371.

33. Benner JS, Glynn RJ, Mogun H, Neumann PJ, Weinstein MC, Avorn J. Long-term persistence in use of statin therapy in elderly patients. JAMA. 2002;288(4):455-461.

34. Balbay O, Annakkaya AN, Arbak P, Bilgin C, Erbas M. Which patients are able to adhere to tuberculosis treatment? A study in a rural area in the northwest part of Turkey. Jpn J Infect Dis. 2005;58(3):152-158.

35. Hirsch-Hoffmann S, Kaufmann C, Banninger PB, Thiel MA. Treatment options for demodex blepharitis: patient choice and efficacy. Klin Monbl Augenheilkd. 2015;232(4):384-387.

36. Kasetsuwan N, Kositphipat K, Busayarat M, et al. Prevalence of ocular demodicosis among patients at Tertiary Care Center, Bangkok, Thailand. Int J Ophthalmol. 2017;10(1):122-127.

37. Madden L, Evans K. Recommending dry eye treatments in community pharmacy. Pharm J. 2017;15:23.

38. Tong L, Beuerman R, Simonyi S, Hollander DA, Stern ME. Effects of punctal occlusion on clinical signs and symptoms and on tear cytokine levels in patients with dry eye. Ocul Surf. 2016;14(2):233-241. 


\section{Supplementary materials}

The video of the live demonstration of the technique is available to view. ${ }^{1}$

Actual questions asked for the interviewer-administered questionnaire on satisfaction levels:

1. Comfort: How comfortable are your eyes during the last week, when you are using the lid wipes?

2. Ease: How easy is it for you to use the lid wipes?

3. Convenience: How convenient is it for you to use the lid wipes?

4. Stinging: Do you experience any stinging when using the eyelid wipes? If yes, how bad is the stinging?

\section{Script for live demonstration}

Now I will be teaching you on how to use the Cliradex lid wipes.

Step 1: Wash your hands and your face. Make sure they are thoroughly clean with soap and cleanser respectively.
Step 2: Dry your hands and face with a clean towel. Ensure that they are completely dry before you apply the lid wipes.

Step 3: Open the lid wipe packet with a downward motion and remove the first lid wipe from the packet. Unfold the lid wipe which had been folded into 4 quadrants. Each packet of lid wipes contain 2 towelettes (one for each eye).

Step 4: Close one eye. Wipe it in a downward motion 3 times using the same side of the towelette. Flip the towelette over. While keeping your eyes closed, wipe it in a similar downward motion 3 times.

You will feel a cool sensation and that is normal. Let the eyelids air dry for a few minutes and the sensation will disappear. You may choose to fan dry your eyelids if you wish.

\section{Reference}

1. Cliradex Lidwipes Demonstration. Video available at: https://youtu.be/ F0z33eoVIqM. Accessed December 19, 2017.
Clinical Ophthalmology

\section{Publish your work in this journal}

Clinical Ophthalmology is an international, peer-reviewed journal covering all subspecialties within ophthalmology. Key topics include: Optometry; Visual science; Pharmacology and drug therapy in eye diseases; Basic Sciences; Primary and Secondary eye care; Patient Safety and Quality of Care Improvements. This journal is indexed on

\section{Dovepress}

PubMed Central and CAS, and is the official journal of The Society of Clinical Ophthalmology (SCO). The manuscript management system is completely online and includes a very quick and fair peer-review system, which is all easy to use. Visit http://www.dovepress.com/ testimonials.php to read real quotes from published authors. 